\title{
Empirical Analysis of ARCH Family Models on Oil Price Fluctuations
}

\author{
Shichang Shen \\ School of Mathematics and Statistics, Qinghai Nationalities University, Xining, China \\ Email: 13909785766@163.com
}

How to cite this paper: Shen, S.C. (2021) Empirical Analysis of ARCH Family Models on Oil Price Fluctuations. Applied Mathematics, 12, 280-286.

https://doi.org/10.4236/am.2021.124019

Received: March 5, 2021

Accepted: April 13, 2021

Published: April 16, 2021

Copyright (c) 2021 by author(s) and Scientific Research Publishing Inc. This work is licensed under the Creative Commons Attribution International License (CC BY 4.0).

http://creativecommons.org/licenses/by/4.0/

\begin{abstract}
This paper selects the daily data of national oil prices from January 2, 2014 to February 28, 2019, establishes an ARMA $(2,0)$ model, and tests its residuals for ARCH effects. Finally, the TARCH $(1,1)$ model is determined to quantitatively analyze the volatility of the crude oil market.
\end{abstract}

\section{Keywords}

Oil Price, ARMA Family Model, Leverage Effect

\section{Introduction}

In recent years, China's development speed has been very rapid, especially in terms of economy, and it has become the second largest economic entity. And oil is more and more important for human beings. Many scholars at home and abroad have done a lot of research on oil price, demand and other factors. Cheng et al. [1] (2018) studied the fluctuation of oil prices by establishing TVP-VAR model. Wu [2] (2018) used STR nonlinear model to explore the asymmetry of oil prices. Zhou [3] (2017) used the ARIMA model to predict oil prices. Shen [4] (2014) identified the economic factors affecting oil prices. Sun [5] (2016) analyzed the impact of economic growth on oil demand and prices. This paper uses EViews7.2 to establish a TARCH model for quantitative analysis of oil prices to determine the impact of different factors on changes in the oil market.

\section{Empirical Analysis}

This article selects the oil price of Zhuochuang Information Oil Network, the unit is USD/barrel. The sample period is from January 2, 2014 to February 28, 2019. Excluding weekends and holidays, and supplementing the missing data accordingly, 1346 valid data were obtained. Use EViews7.2 for empirical analysis 
of the data [6] [7] $(2009,2010)$.

\subsection{Data Processing}

As can be seen from Figure 1, the price of oil was more than 100 USD/barrel at the beginning of 2014, but the price had fallen below $30 \mathrm{USD} /$ barrel at the end of 2015. The price of oil showed a significant downward trend during this period It shows that the oil market has been greatly impacted during this period. From 15 to 19 years, the price of oil showed a small increase, especially in 18 years the price reached the highest in recent years. It can also be observed from the figure that there is obvious asymmetry and non-stationarity in oil prices.

To change the oil price series into a stationary series, a second-order difference is required to effectively remove the influence of trends and other factors.

It can be seen from Figure 2 that the sequence has reached a plateau. It can also be seen that the sequence has obvious clustering and continuity. A large fluctuation is followed by a larger one, and a small fluctuation is followed by a smaller one.

From the results in Table 1, we know that the series passed the ADF test, and the test criteria are no intercept term and time trend term. The ADF statistic is

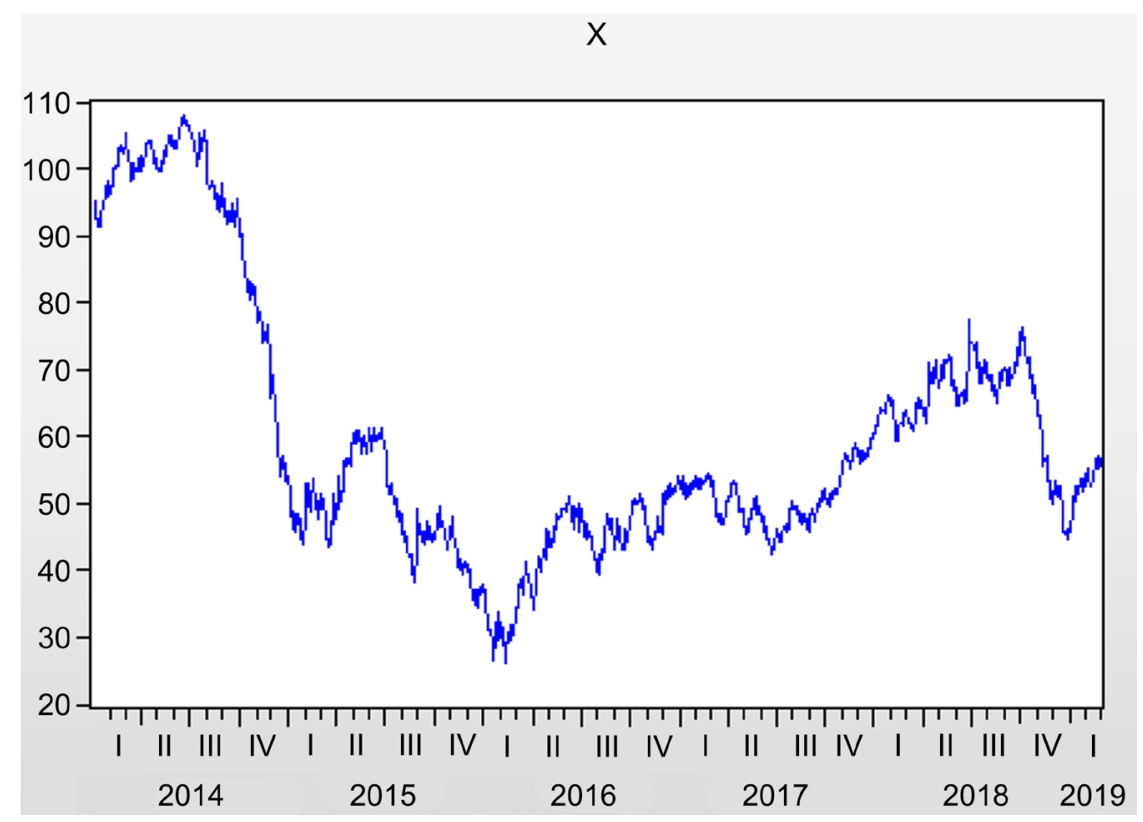

Figure 1. Price trend of oil from January 2, 2014 to February 28, 2019.

Table 1. Stationarity test of oil price series.

\begin{tabular}{cccc}
\hline & & ADF & P value \\
\hline Unit Root Test & & -21.39261 & 0.0000 \\
\hline \multirow{2}{*}{ Test key figure } & $1 \%$ level & -2.566695 & \\
& $5 \%$ level & -1.941061 & \\
& $10 \%$ level & -1.616540 & \\
\hline
\end{tabular}




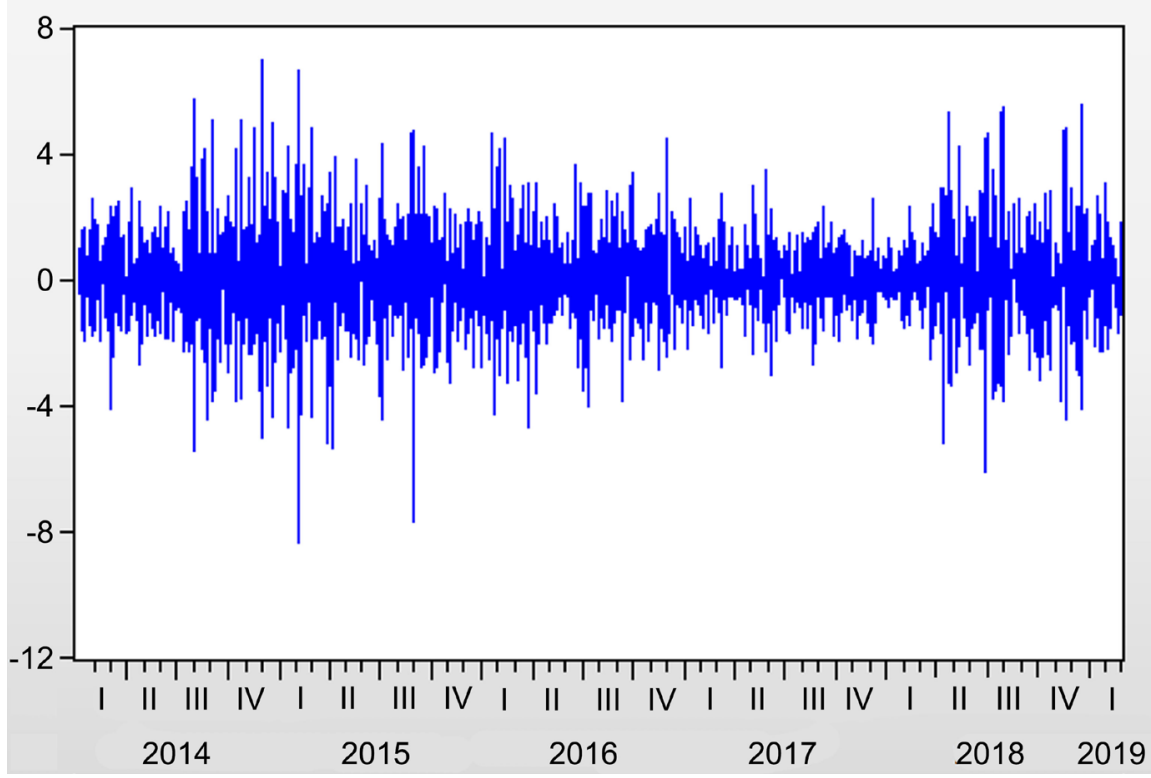

Figure 2. Stationary chart of oil prices.

-21.39261 , which is less than $-2.666695,-1.941061,-1.616540$; the $\mathrm{P}$ value is 0 , indicating that the sequence at this time is stable, and the sequence can be modeled and analyzed.

\subsection{Normality Test}

Calculate each statistic for the sequence.

As can be seen from Figure 3, the distribution of the sequence is different from the normal distribution. Its mean value is -0.028201 , which is not 0 , which does not satisfy the basic assumption of normal distribution. The skewness is -0.156229 , indicating that the sequence is skewed to the left; the kurtosis is 4.860388 , which is greater than the maximum kurtosis value 3 of the normal distribution, which shows the characteristics of peaks; the value of the JB statistic is 199.4339, and its $\mathrm{P}$ value is 0 , Further shows that the distribution of this sequence is different from the normal distribution.

\subsection{ARCH Effect Test}

In order to investigate whether the oil price series has an ARCH effect, it is necessary to first establish a mean equation for the series. By establishing a time series model (ARMA model) on the series, it can be determined from the correlation diagram of the series that the series meets the ARMA $(2,0)$ model. From this, the mean equation of the model can be established:

$$
Z_{t}=-0.708984 Z_{t-1}-0.346645 Z_{t-2}+\mu_{t}
$$

Then, perform a first-order and a second-order sequence autocorrelation test on the residual sequence $\mu_{t}$, and find that the $\mathrm{P}$ value of the sequence is close to 0 , indicating that the residual sequence has an ARCH effect. Assuming that the 


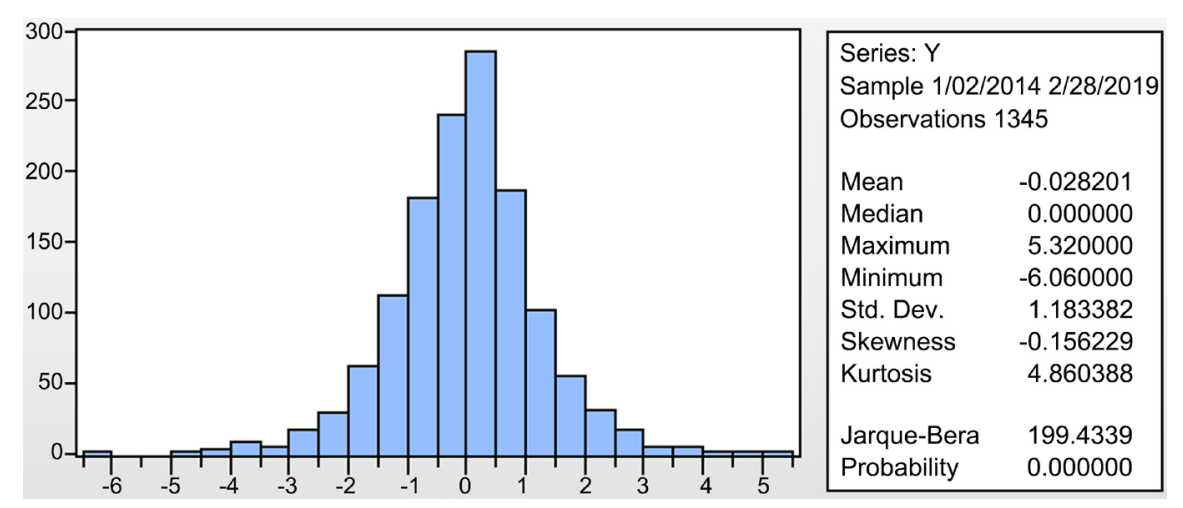

Figure 3. Statistics of the sequence.

sequence is in the seventh-order autocorrelation test, the LM statistics It is still significant, indicating that the sequence may have high-order ARCH effects, as shown in Table 2.

The $P$ value of the 7th order autocorrelation test in Table 2 is still 0 , which meets the previous assumptions. It shows that the sequence still has ARCH effect in the high-order autocorrelation test, then the sequence must have high-order $\mathrm{ARCH}$ effect, and an $\mathrm{ARCH}$ model can be established for the residual sequence.

\subsection{Model Recognition}

When the residual sequence $\mu_{t}$ still passes the 7th order autocorrelation test, a GARCH model can be fitted to the sequence. The ARCH effect is very significant in the order of $1-7$, the GARCH term can be 1 , and the ARCH term is also 1 , then GARCH $(1,1)$ can be fitted. However, after judging by the AIC and SC criteria, it is found that the fitting effect of the GARCH $(1,1)$ model is not very good, and from Figure 1 it can be observed that the oil price has fallen dramatically in 14 years, and the sequence as a whole Asymmetric features. Therefore, TARCH and EARCH models should be established for the residual series to describe the fluctuation of the oil market.

From the results in Table 3, the log-likelihood function value of the TARCH model is larger at -2256.888 , while the values of AIC and SC are smaller at 3.372411 and 3.395668 , so a TARCH $(1,1)$ model can be established to describe petroleum Price fluctuations.

It can be known from the results in Table 4 that most of the $\mathrm{P}$ values of the coefficients in the TARCH $(1,1)$ model are 0 , which is very significant, and it can be considered that the TARCH model works well. Then establish its mean equation and variance equation:

Mean equation: $Z_{t}=-0.703686 Z_{t-1}-0.357517 Z_{t-2}+\varepsilon_{t}$.

Variance equation:

$\sigma_{t}^{2}=0.025843+0.102529 u_{t-1}^{2}-0.085770 u_{t-1}^{2} d_{t-1}+0.929366 \sigma_{t-1}^{2}$.

In the variance equation, $\alpha=0.102529, \gamma=-0.085770$.

When there is good news $\left(u_{t-1}>0\right), d_{t-1}=0$, the asymmetric term does not exist, there is only a shock of 0.102529 times, and when there is bad news 
Table 2. LM test for sequence $\mu_{t}$.

\begin{tabular}{cccc}
\hline F Statistic & 45.82596 & P value & 0.0000 \\
\hline R-squared & 260.3044 & R-squared P-value & 0.0000 \\
\hline
\end{tabular}

Table 3. Model recognition.

\begin{tabular}{cccc}
\hline & Log-likelihood function & AIC & SC \\
\hline $\operatorname{TARCH}(1,1)$ & -2256.888 & 3.372411 & 3.395668 \\
$\operatorname{EARCH}(1,1)$ & -2259.977 & 3.377015 & 3.400273 \\
\hline
\end{tabular}

Table 4. Parameter estimation of the TARCH model.

\begin{tabular}{ccccc}
\hline Variable & Coefficient & Std. Error & z-Statistic & Prob. \\
\hline AR(1) & -0.703686 & 0.027174 & -25.89854 & 0.0000 \\
AR(2) & -0.357517 & 0.024887 & -14.36541 & 0.0000 \\
& \multicolumn{2}{c}{ Variance Equation } & \\
$\omega$ & 0.025843 & 0.010061 & 2.568599 & 0.0102 \\
$\alpha$ & 0.102529 & 0.012714 & 8.064075 & 0.0000 \\
$\gamma$ & -0.085770 & 0.019019 & -4.509709 & 0.0000 \\
$\beta$ & 0.929366 & 0.011951 & 77.76738 & 0.0000 \\
R-squared & 0.363932 & Mean dependent var & $7.45 \mathrm{E}-05$ \\
Adjusted R-squared & 0.363457 & S.D. dependent var & 1.717852 \\
S.E. of regression & 1.370565 & Akaike info criterion & 3.372411 \\
Sum squared resid & 2517.119 & Schwarz criterion & 3.395668 \\
Log likelihood & -2256.888 & Hannan-Quinn criter. & 3.381123 \\
Durbin-Watson stat & 2.206053 & & \\
Inverted AR Roots & $-0.35+0.48 \mathrm{i}$ & -0.35 - 0.48i & \\
\hline
\end{tabular}

$\left(u_{t-1}<0\right), d_{t-1}=1$, the asymmetric term exists, there will be a shock of 0.0116759 times. Because $\gamma<0$, the effect of asymmetric effects reduces fluctuations.

\subsection{Adaptability Test of Residuals}

After analyzing and determining the establishment of the TARCH $(1,1)$ model, it is necessary to perform an ARCH effect test on the residual term $\varepsilon_{t}$ of the mean equation of the model. ARCH-LM test was performed on the TARCH (1, 1) model. The results are shown in Table 5 .

From the results in Table 5, it can be seen that the P value of the LM test for the residual term $\varepsilon_{t}$ of the mean equation is 0.5757 , which is larger than the value of the significance level of $5 \%$, indicating that the residual series are independent and there is no $\mathrm{ARCH}$ effect, that is, the oil price series meet The TARCH $(1,1)$ model can effectively explain the fluctuation of the oil market. 
Table 5. Adaptability test for sequence $\varepsilon_{t}$.

\begin{tabular}{cccc}
\hline F Statistic & 0.312780 & P value & 0.5761 \\
\hline R-squared & 0.313174 & R-squared P-value & 0.5757 \\
\hline
\end{tabular}

\section{Conclusions}

After empirical analysis of the selected data interval, it was found that after 14 years of sharp decline in oil prices, there have been signs of a steady rise in the past $4-5$ years. In addition, after performing the ARCH effect test on the oil price residual sequence, it was found that the sequence has a significant "spike tail" phenomenon, and the residual sequence has a high-order ARCH effect. After further analysis, it is found that the residual sequence also has asymmetry. This phenomenon is very significant, so the TARCH $(1,1)$ model is established for the sequence. It can be known from the parameter estimates of the model that the negative asymmetry coefficient of the model will gradually reduce the fluctuation of oil prices. When the good news appears, the impact on oil prices will be greater than that when the bad news appears. Such fluctuations will gradually stabilize.

From the above empirical analysis, it can be more clearly realized that the phenomenon that the oil market is affected by different factors is different. Through the analysis of specific phenomena, relevant measures can be formulated to regulate oil prices, thereby accelerating China's modernization.

\section{Funds}

This work is supported by the National Natural Science Foundation of China (No. 11561056) and Natural Science Foundation of Qinghai (No. 2016-ZJ-914).

\section{Conflicts of Interest}

The author declares no conflicts of interest regarding the publication of this paper.

\section{References}

[1] Cheng, L.Y. and Li, J.K. (2018) Passive Differentiation of International Oil Prices to Economic Passion and Multi-Spot Impact-Testing Based on TVP-VAR Model. Systems Engineering, No. 9, 101-110.

[2] Wu, M.Q. (2018) Research on the Asymmetric Effect of the Fluctuation of International Crude Oil Price on China's Output. Jiangxi University of Finance and Economics, No. 1, 1-46.

[3] Zhou, Y. (2017) Application of ARIMA Model in Forecasting and Analyzing Oil Price. Northern Economy and Trade, No. 8, 23-24.

[4] Shen, X.F. (2014) Analysis of Influencing Factors of International Crude Oil Price Fluctuations. Knowledge Economy, No. 7, 71-72.

[5] Sun, Y.R. (2016) Econometric Analysis of the Impact of Economic Growth on Oil Demand and Oil Prices. Modern Economic Information, No. 8, 364. 
[6] Gao, T.M. (2009) Methods and Models of Econometric Analysis-EViews Application and Example. 2nd Edition, Tsinghua University Press, Beijing.

[7] Wang, Z.H.L. (2010) Applied Time Series Analysis. China Statistics Press, Beijing. 